\title{
Biomarkers of Prostatic Cancer: An Attempt to Categorize Patients into Prostatic Carcinoma, Benign Prostatic Hyperplasia, or Prostatitis Based on Serum Prostate Specific Antigen, Prostatic Acid Phosphatase, Calcium, and Phosphorus
}

\author{
Shahana Sarwar, ${ }^{1}$ Mohammed Abdul Majid Adil, ${ }^{2}$ \\ Parveen Nyamath, ${ }^{3}$ and Mohammed Ishaq ${ }^{3}$ \\ ${ }^{1}$ Department of Biochemistry, Owaisi Group of Hospitals, DCMS, Hyderabad, Telangana, India \\ ${ }^{2}$ Department of Urology, Owaisi Group of Hospitals, DCMS, Hyderabad, Telangana, India \\ ${ }^{3}$ Salar-e-Millat Research Centre, PEH, DCMS, Hyderabad, Telangana, India \\ Correspondence should be addressed to Mohammed Abdul Majid Adil; drmamadil@yahoo.co.in
}

Received 17 May 2016; Revised 24 August 2016; Accepted 25 October 2016; Published 12 January 2017

Academic Editor: Weide Zhong

Copyright (c) 2017 Shahana Sarwar et al. This is an open access article distributed under the Creative Commons Attribution License, which permits unrestricted use, distribution, and reproduction in any medium, provided the original work is properly cited.

Prostatitis, BPH, and P.Ca are the most frequent pathologies of the prostate gland that are responsible for morbidity in men. Raised levels of PSA are seen in different pathological conditions involving the prostate. PAP levels are altered in inflammatory or infectious or abnormal growth of the prostate tissue. Serum calcium and phosphorus levels were also found to be altered in prostate cancer and BPH. The present study was carried out to study the levels of PSA, PAP, calcium, and phosphorus in serum of patients with Prostatitis, BPH, or P.Ca and also to evaluate the relationship between them. Males in the age group of 50-85 years with LUTS disease symptoms and with PSA levels more than $4 \mathrm{ng} / \mathrm{mL}$ were included. A total of 114 patients were analyzed including 30 controls. Prostatitis in $35.7 \%$ of cases, BPH in $35.7 \%$ of the cases, and P.Ca in $28.57 \%$ of the cases were observed. Thus, the nonmalignant cases constitute a majority. PSA, a marker specific for prostatic conditions, was significantly high in all the diseases compared to controls. A rise in serum PSA and PAP indicates prostatitis or, in combination with these two tests, decreased serum calcium shows advanced disease.

\section{Introduction}

The diseases associated with prostate are prostatitis, benign prostatic hyperplasia (BPH), and prostate cancer (P.Ca) which leads to several metabolic disturbances. P.Ca is the second dreadful cancer in the world, common among men in US. Annually more than 2,30,000 men are diagnosed and approximately 30,000 die from it. African American men have high incidence of P.Ca and 60\% more likely to develop when compared to Caucasian. It affects the young men with positive family history of P.Ca when compared to individuals without history. Men above 45 years are prone to $\mathrm{BPH}$, a universal phenomenon which increases with age. Various factors are responsible for the prostate diseases in men especially elders $[1,2]$. Screenings for P.Ca include serum PSA and digital rectal examination (DRE); a biopsy is required to diagnose P.Ca. The histopathological diagnosis of prostate cancer will only confirm the final diagnosis in 67\% of cases whereas $33 \%$ are diagnosed with the other modalities [3].

Early detection and treatment in asymptomatic men may improve the mortality rate and the quality of life. Screening for markers such as prostate specific antigen (PSA) and prostate acid phosphatase (PAP) resulted in detection and treatment of the disease at an earlier stage.

Men of 50 years of age or above without any family history of cancer and those at 40 years of age with family history must undergo digital rectal examination (DRE) and PSA levels should be checked annually as recommended by of American Urological Association (AUA) and Food and Drug Administration (FDA). 
The screening of PSA is not a common practice in India. The patients visiting department of urology of a hospital with complaints of lower urinary tract symptoms (LUTS) are checked for their PSA levels. Various studies reported that men with LUTS have the same risk of having P.Ca as asymptomatic men of the same age and have an increased risk of unnecessary biopsy if the threshold is taken as the same as that in case of the symptomatic men [4-6].

Several studies reported that markers such as PSA and PAP were used for confirming and monitoring P.Ca. PSA is one of the organ specific tumor markers produced by prostatic tissue [7]. In patients with BPH, PSA levels can increase 2-3 times the normal. The major limitation for using PSA, as a screening prostate cancer biomarker, is that majority of the men suffer from $\mathrm{BPH}$ and prostatitis as they become old, which increases their serum PSA levels. Therefore, PSA alone cannot be used as a biomarker for cancer detection. The elevated levels of PSA do not indicate cancer but the higher the PSA level, the more the chance of having cancer.

PAP is a tumor marker produced by the lysosomes of the prostate's epithelial cells [8]. The levels of PAP are high in 60\% of men with P.Ca with metastases. However, the level of PAP in the serum is normal or slightly high when the carcinoma remains localized in the prostate gland and is elevated in some benign condition such as $\mathrm{BPH}$ and osteoporosis.

The association between high levels of serum calcium and risk of P.Ca has been demonstrated by various investigators [9]. The high level of calcium in serum is due to decrease in apoptosis and an increase in proliferation of P.Ca cells responsible for growth and metastasis. The increase in serum calcium or any factor that leads to it would increase the possibility for terminal P.Ca as has been reported by several researchers. Thus, analysis of calcium in serum may be used as a promising prospective biomarker for screening for P.Ca.

Several studies have reported a positive association between phosphorus intake and P.Ca [10, 11]. A recent study by Wilson et al. showed that calcium and phosphorus have independent effects at different time periods between exposure and diagnosis of P.Ca [12].

There is a need to use combination of markers and tests which can save the patient from unnecessary biopsies.

The present study was carried out to categorize the patients into prostatic carcinoma, benign prostatic hyperplasia, or prostatitis based on serum prostate specific antigen, prostatic acid phosphatase, calcium and phosphorus levels, and DRE and to evaluate the discriminating power of these in distinguishing controls and cases to reduce the risk of unnecessary biopsy. The diagnostic efficiency (DE) of these markers was confirmed by analyzing their sensitivity and specificity using receptor operative curves (ROC).

\section{Methods}

The study was approved by Institutional Ethical Committee. The informed consent was obtained from the patients. The patients with LUTS visiting the Department of Urology at Owaisi group of hospitals and research centre were enrolled in the study. A total of 114 subjects were included in the study. 84 patients served as cases whereas age and sex matched 30 individuals were selected from ENT, dental, and gastroenterology departments of the same hospital with complaints of disease other than LUTS and served as controls. From each department, 10 subjects were included.

2.1. Inclusion Criteria. Male patients in the age group of 50 85 years with LUTS and with PSA levels more than normal value (i.e. $>4 \mathrm{ng} / \mathrm{mL}$ ) were included. Age and sex matched persons without LUTS served as controls.

2.2. Exclusion Criteria. Patients with acute LUTS with fever and other symptoms, documented UTI, established cases of P.Ca, BPH and prostatitis, or history of previous biopsy or urological procedure were excluded.

The clinical diagnosis of prostatic disease was based on LUTS, elevated levels of PSA, DRE, TRUS, and TRUS guided biopsy, and histopathological examination of the biopsied tissue. The blood was collected at initial presentation in order to avoid any stimulation of the prostatic gland, which may increase PSA levels. Then, the patients were categorized into prostatitis, $\mathrm{BPH}$, and P.Ca.

2.3. Sample Collection. $10 \mathrm{~mL}$ of venous blood (fasting) was collected under aseptic conditions in the plain tubes. Serum was used for the analysis of PSA, PAP, calcium, and phosphorus.

2.4. Procedure. Serum PSA was measured using commercially available kits based on enzyme immunoassay for the quantitative determination by Pathozyme ELISA [13]. The estimation of PAP was done by Kinetic method [14], calcium by O-cresolphthalein complexone method and End Point Assay [15], and the level of phosphorus was done by UV-End point method [16]. The ROC was plotted by Youden Index, to calculate the best cutoff value.

\section{Results}

The age of the subjects were given in the age range of 50-85 years (Table 1).

The mean values for PSA, PAP, and calcium are significantly higher in cases than controls (Table 2). The comparison of PSA and PAP levels in between the groups revealed that the levels are significantly higher in prostatitis as compared to $\mathrm{BPH}$ and controls. The level of PAP was significantly higher in prostatic carcinoma as compared to prostatitis. The serum calcium level was higher in BPH group when compared to prostate carcinoma. The phosphorus level was significantly more in BPH than controls.

In order to assess the maximum sensitivity, specificity, and $\mathrm{DE}$ of various parameters in identifying abnormality, the best cutoff values (BCV) were calculated using ROC analysis (Figures 1 and 2, Tables 3 and 4). The analysis of prostate gland in patients of various groups based on digital rectal examination (DRE) was given in Table 5. The PSA levels and 
TABLE 1: The number of patients in each group along with their age.

\begin{tabular}{|c|c|c|c|c|c|}
\hline \multirow{2}{*}{ Group } & \multicolumn{5}{|c|}{ Age (years) } \\
\hline & $50-59$ & $60-69$ & $70-79$ & $80+$ & Total \\
\hline Controls & 7 & 9 & 12 & 2 & 30 \\
\hline Prostatitis & 13 & 11 & 5 & 1 & 30 \\
\hline BPH & 8 & 11 & 6 & 5 & 30 \\
\hline P.Ca & 3 & 8 & 9 & 4 & 24 \\
\hline
\end{tabular}

This table shows the age range of patients and controls included in the study. A total of 114 patients were included in the study. The individuals were grouped into 4 groups based on the age range which was from 50 to 85 years.

TABLE 2: The table shows the mean levels of various biomarkers in different groups.

\begin{tabular}{lcccc}
\hline Group & PSA $(\mathrm{ng} / \mathrm{mL})$ & PAP $(\mathrm{IU} / \mathrm{L})$ & Calcium $(\mathrm{mg} / \mathrm{dL})$ & Phosphorus $(\mathrm{mg} / \mathrm{dL})$ \\
\hline Control & $2.27 \pm 1.06$ & $2.5 \pm 1.12$ & $8.94 \pm 0.74$ & $3.41 \pm 0.91$ \\
Prostatitis & $52 \pm 6.45$ & $11.4 \pm 2.34$ & $9.08 \pm 0.93$ & $3.77 \pm 1.1$ \\
BPH & $11.15 \pm 2.23$ & $3.9 \pm 1.34$ & $9.23 \pm 0.78$ & $4.85 \pm 1.8$ \\
Prostate Carcinoma & $70.64 \pm 6.54$ & $25.1 \pm 3.4$ & $8.45 \pm 0.85$ & $3.5 \pm 1.98$ \\
\hline
\end{tabular}

The table showed the levels of biochemical parameters in different groups. The levels of PSA and PAP were higher in P.Ca group as compared to the others.

TABLE 3: The sensitivity and specificity of various biomarkers in different groups are given in the table.

\begin{tabular}{|c|c|c|c|c|c|}
\hline Parameter & & Control versus total & Prostatitis versus $\mathrm{BPH}$ & $\mathrm{BPH}$ versus P.Ca & Prostatitis versus P.Ca \\
\hline \multirow{3}{*}{ PSA (ng/mL) } & Best cutoff & 4.75 & 16.75 & 22.5 & 36.3 \\
\hline & Sensitivity & 100 & 70 & 99.2 & 70.8 \\
\hline & Specificity & 100 & 83.3 & 96.2 & 50 \\
\hline \multirow{3}{*}{$\mathrm{PAP}(\mathrm{IU} / \mathrm{L})$} & Best cutoff & 4.05 & 6.35 & 10.5 & 19.5 \\
\hline & Sensitivity & 76.2 & 90 & 87.5 & 79.2 \\
\hline & Specificity & 96.7 & 90 & 100 & 93 \\
\hline \multirow{3}{*}{ Calcium (mg/dL) } & Best cutoff & 8.95 & 10.6 & 5.8 & 5.8 \\
\hline & Sensitivity & 47.6 & 6.7 & 100 & 100 \\
\hline & Specificity & 63.3 & 100 & 0 & 0 \\
\hline \multirow{3}{*}{ Phosphorus (mg/dL) } & Best cutoff & 4.35 & 6.65 & 5.55 & 3.1 \\
\hline & Sensitivity & 42.9 & 99.9 & 4.25 & 70.8 \\
\hline & Specificity & 93.3 & 96.3 & 86.7 & 40 \\
\hline
\end{tabular}

The table shows the sensitivity and specificity pattern of PSA and PAP in different groups. At BCV $4.75 \mathrm{ng} / \mathrm{mL}$, the PSA showed $100 \%$ sensitivity and specificity whereas at BCV $4.05 \mathrm{IU} / \mathrm{L}$ PAP showed $76.2 \%$ sensitivity and $96.7 \%$ specificity. BCV at $5.8 \mathrm{mg} / \mathrm{dL}$ calcium showed $100 \%$ sensitivity in BPH versus P.Ca and prostatitis versus P.Ca.

staging of prostate carcinoma patients in different age groups were given in Table 6.

In cases and controls,

PSA, at bcv $4.75 \mathrm{ng} / \mathrm{mL}$, showed 100\% sensitivity and specificity,

PAP, at bcv $4.05 \mathrm{IU} / \mathrm{L}$, showed $76 \%$ sensitivity and $96 \%$ specificity,

serum phosphorus $4.35 \mathrm{mg} / \mathrm{dL}$ showed specificity of $93 \%$.

In prostatitis and $\mathrm{BPH}$,

PSA, at bcv $16.75 \mathrm{ng} / \mathrm{mL}$, showed 70\% sensitivity and $83.3 \%$ specificity,
PAP, at bcv $6.35 \mathrm{IU} / \mathrm{L}$, showed $90 \%$ sensitivity and specificity,

serum calcium $10.6 \mathrm{mg} / \mathrm{dL}$ showed $100 \%$ specificity, phosphorus $6.65 \mathrm{mg} / \mathrm{dL}$ showed $99.9 \%$ sensitivity and $96.7 \%$ specificity.

In $\mathrm{BPH}$ and $\mathrm{P} . \mathrm{Ca}$,

PSA, at bcv $22.5 \mathrm{ng} / \mathrm{mL}$, showed $99.27 \%$ sensitivity and $96.7 \%$ specificity,

PAP, at bcv $10.5 \mathrm{IU} / \mathrm{L}$, showed $87.5 \%$ sensitivity and $100 \%$ specificity,

serum calcium, $5.8 \mathrm{mg} / \mathrm{dL}$, showed $100 \%$ sensitivity. 

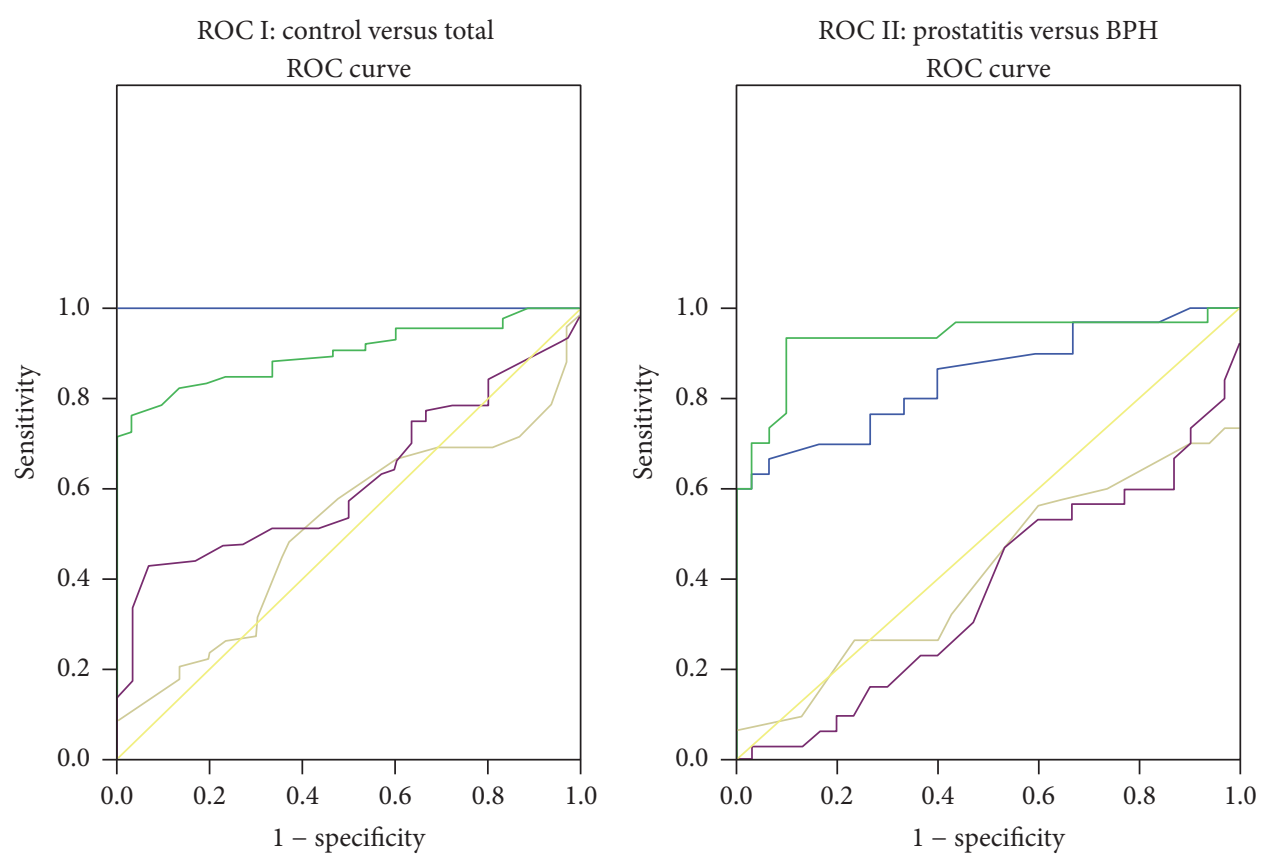

Source of the curve

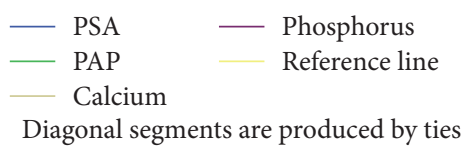

Source of the curve

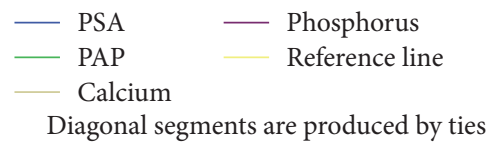

FIGURE 1: Receptor operative curves.
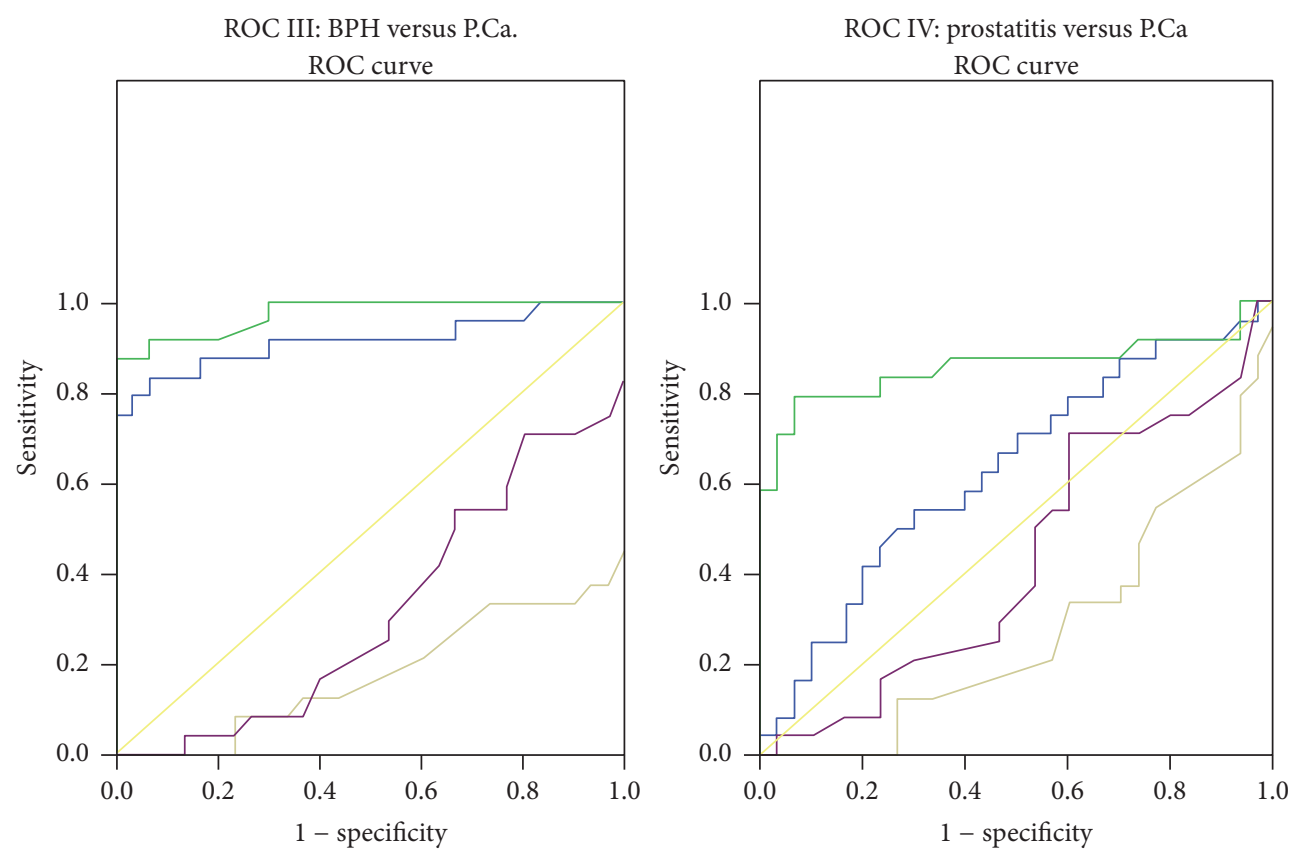

Source of the curve

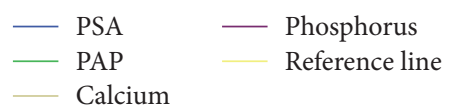

Source of the curve

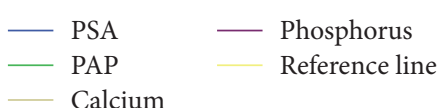

FIGURE 2: Receptor operative curves. 
TABLE 4: The percentage of diagnostic efficiency (DE).

\begin{tabular}{lccc}
\hline Parameter & $\begin{array}{c}\text { Control versus } \\
\text { total }\end{array}$ & $\begin{array}{c}\text { Prostatitis versus } \\
\mathrm{BPH}\end{array}$ & $\begin{array}{c}\mathrm{BPH} \text { versus } \\
\text { P.Ca }\end{array}$ \\
\hline PSA & $100 \%$ & $76.6 \%$ & $59.2 \%$ \\
PAP & $82.4 \%$ & $90 \%$ & 83.35 \\
\hline
\end{tabular}

The table showed the percentage of diagnostic efficiency of PSA and PAP in cases and controls. Serum PSA showed $100 \%$ DE in total cases and control whereas PAP showed only $82.4 \%$. PSA showed DE of $76.6 \%$ and $59.2 \%$ in prostatitis versus $\mathrm{BPH}$ and $\mathrm{BPH}$ versus $\mathrm{P}$.Ca, respectively, whereas DE of PAP was $90 \%$ and $83.3 \%$ in the above groups.

In prostatitis and P.Ca,

PSA, at bcv $36.3 \mathrm{ng} / \mathrm{mL}$, showed $70.8 \%$ sensitivity and $50 \%$ specificity,

PAP, at bcv $19.5 \mathrm{IU} / \mathrm{L}$, showed $79.2 \%$ sensitivity and 93\% specificity,

serum calcium $5.8 \mathrm{mg} / \mathrm{dL}$ showed $100 \%$ sensitivity and no specificity.

\section{Discussion}

Prostate cancer, prostatitis, and $\mathrm{BPH}$ are the most frequent pathologies of the prostate gland, whose management strategies are diametrically different. P.Ca is the most frequently diagnosed malignancy in men and the second leading cause of cancer deaths especially in Western countries [1]. There is lack of epidemiological data on the exact prevalence of this disease in India due to lack of proper screening and underrecorded incidence of P.Ca. On the other hand, BPH and prostatitis are the other two most frequent pathologies of prostate gland that clinically/symptomatically mimic prostate cancer. P.Ca is notoriously difficult to treat, which makes its early detection a priority. There is an urgent need for appropriate diagnostic and prognostic markers to detect P.Ca and to differentiate it from other pathologies of prostate gland. The present study was undertaken to assess the levels of PSA, PAP, calcium, and phosphorus in different pathologies of prostate gland, in an attempt to use a combination of markers to differentiate the above conditions to avoid the use of unnecessary biopsies. Our observations revealed that PSA was significantly high in cases than controls $(p<0.001)$. These findings correlated with the studies by Jung et al. and Anim et al. confirming the increased levels of PSA in different pathologies of prostate gland $[17,18]$.

The discovery of PSA as a biomarker and demonstration of its utility in early diagnosis and monitoring of P.Ca date back to the early 1980s. However, the use of only PSA as an initial diagnostic tool has become controversial over the past decade due to its increased levels in other pathologies of prostate. This view is supported by our findings of significantly higher increase in PSA in prostatitis and prostate cancer compared to controls and $\mathrm{BPH}$. The above marker, though it remains an early signal for the pathologies of prostate, may lead to overdiagnosis which in turn would result in over and aggressive treatment strategies. PAP was significantly increased in cases compared to controls $(p<0.001)$.
TABLE 5: The analysis of prostate gland in patients of various groups based on digital rectal examination (DRE).

\begin{tabular}{lcl}
\hline Group & $\begin{array}{c}\text { Number of } \\
\text { patients }\end{array}$ & DRE details \\
\hline $\begin{array}{l}\text { Control } \\
(n=30)\end{array}$ & 15 & $\begin{array}{l}\text { Normal, firm, nontender prostate with } \\
\text { maintained landmarks }\end{array}$ \\
& 13 & $\begin{array}{l}\text { Grade I-II, nontenderness and } \\
\text { maintained land marks } \\
\text { Grade III-IV, prostatomegaly }\end{array}$ \\
& 16 & $\begin{array}{l}\text { Grade I-II prostatic enlargement with } \\
\text { mild to moderate tenderness with } \\
\text { maintained land marks } \\
\text { Grostatitis } \\
(n=30)\end{array}$ \\
& 7 & $\begin{array}{l}\text { Grade II with no tenderness with } \\
\text { maintained landmarks } \\
\text { Grade III-IV with mild to moderate } \\
\text { tenderness and normal landmarks, firm } \\
\text { consistency } \\
\text { Grade III-IV with severe tenderness and } \\
\text { soft prostate consistency }\end{array}$ \\
\hline $\begin{array}{l}\text { BPH } \\
(n=30)\end{array}$ & 12 & $\begin{array}{l}\text { Grade I-II } \\
\text { Grade III } \\
\text { Grade IV, firm, nontender with } \\
\text { maintained landmarks (median groove, } \\
\text { etc.), no induration }\end{array}$ \\
\hline
\end{tabular}

Our findings were in agreement with the earlier studies by Taira et al. [19] and Nguyen et al. [20] thereby confirming the increased levels of PAP in different pathologies of prostate gland.

PAP emerged as the world's first clinically useful tumor marker in the 1940s and 1950s. With the introduction of the PSA test in the 1980s, which performed significantly better than PAP in terms of screening and monitoring response to treatment, PAP fell into disfavor. The recent studies have identified PAP as a significant prognostic factor for patients with intermediate and high-risk prostate cancer. PAP was known to have a low sensitivity for diagnosing new disease. In a study it was found that PAP has low sensitivity compared to PSA [21]. Since the goal of P.Ca screening is to identify early-stage treatable disease, PAP was rightly dropped as a screening tool. Several studies suggest that PAP could play a role in determining which early-stage patients are likely to benefit from more aggressive adjuvant therapy [21]. This view is supported by our findings of significantly higher increase in $\mathrm{PAP}$ in prostatitis and P.Ca compared to controls and $\mathrm{BPH}$; in addition, we also observed significant increase in serum PAP in prostate cancer compared to prostatitis.

Moreover, it was observed that, at cutoff value of $4.75 \mathrm{ng} / \mathrm{mL}$, PSA is indicative of prostate gland pathology at a sensitivity and specificity of $100 \%$ and DE of $100 \%$ which may lead to differentiating any pathology. However, the DE in discriminating prostatitis from $\mathrm{BPH}$ is $76.6 \%$, between P.Ca and $\mathrm{BPH}$ is $90.7 \%$, and between prostatitis and P.Ca is only $59.2 \%$. Thus, the discriminating or diagnosing power of PSA into the type of pathology is limited. Our findings were in accordance with those of Yaman et al. and Simardi et al. who related the PSA elevation to pathologies of prostate 
TABLE 6: The PSA levels and staging of prostate carcinoma patients.

\begin{tabular}{lccccc}
\hline Age (years) & Number of patients & PSA $(\mathrm{ng} / \mathrm{mL})$ & TNM staging & Stage & Gleason score \\
\hline $50-59$ & 3 & 66.75 & $\mathrm{~T}_{1} \mathrm{~N}_{0} \mathrm{M}_{0}$ & I-II & $3+3=6$ \\
$60-69$ & 8 & 68.82 & $\mathrm{~T}_{1} \mathrm{~N}_{1} \mathrm{M}_{0}$ & II-III & $4+4=8$ \\
& 4 & 78.45 & $\mathrm{~T}_{3} \mathrm{~N}_{1} \mathrm{M}_{1}$ & III-IV & $5+4=9$ \\
$70-79$ & 5 & 76.62 & $\mathrm{~T}_{3} \mathrm{~N}_{X} \mathrm{M}_{1}$ & III-IV & $3+4=7$ \\
$80+$ & 4 & 70.46 & $\mathrm{~T}_{2} \mathrm{~N}_{0} \mathrm{M}_{1}$ & I-II & $3+4=7$ \\
\hline
\end{tabular}

The table showed the TNM (tumor, lymph nodes, and metastases) staging and Gleason score in patients of various age groups. The level of PSA was also included.

tissues [22, 23]. It was also observed that, at a cutoff value of $4.05 \mathrm{IU} / \mathrm{L}, \mathrm{PAP}$ is indicative of prostate gland pathology at a sensitivity of $76.2 \%$ and specificity of $96.7 \%$ in discriminating cases from controls and a DE of $82.4 \%$. Thus, PAP was found to have a better discriminating power into the type of pathology. Its DE to differentiate between prostatitis and $\mathrm{BPH}$ is $90 \%$, between $\mathrm{BPH}$ and P.Ca is $94.4 \%$, and prostatitis from P.Ca is $85.5 \%$.

A rise in PSA and PAP, in combination, indicates either prostatitis or P.Ca and rules out BPH. In combination to these two, a decrease in serum calcium is indicative of advanced disease in prostate cancer. This is in accordance with the findings of Kukreja et al. which show a significant decrease in P.Ca [9]. According to them, in patients with solid tumors like prostate, breast, or lung cancer, hypocalcaemia develops due to extensive osteoblastic metastases. Raskin et al. performed a retrospective analysis of serum calcium levels in patients with metastatic bone disease and reported a 33\% prevalence of hypocalcaemia in patients with prostate cancer [24]. This is also in accordance with study by Szentirmai et al. which revealed that few patients with prostate cancer and bone metastases have a low serum calcium concentration, and some have severe hypocalcaemia [25]. Avid calcium uptake by osteoblastic bone metastases was postulated more than 30 years ago by Ludwig [26]. The hypocalcaemia in these patients may be most likely on the basis of extensive accretion of calcium into bones. Serum total calcium was significantly lower in patients with bone metastasis than those without. In this case, hypocalcaemia can be explained on the basis of hypoalbuminemia or renal failure. Therefore, apparent hypocalcaemia based on total calcium measurement is common in patients with P.Ca [9]. Men whose blood calcium levels fall at the high end of the normal range are more likely to develop 2.5 times fatal P.Ca when compared to men with lower levels, according to a recent study. If confirmed by other studies, the findings could have important implications for the prevention and treatment of P.Ca [27].

It has been known for many years that hypocalcaemia can occur in patients with osteoblastic metastases from prostate cancer. Ludwig postulated the following sequence: osteoblastic metastases cause increased deposition of calcium and phosphate in bone, tending to decrease serum concentrations of both ions [27]. P.Ca, BPH, and prostatitis are common prostatic clinical conditions whose management strategies are diametrically different. The final areas in differentiating these conditions are biopsy. Biopsies (8-10 needle core) have its own complications and side effects.
Though PSA has emerged as marker for prostatic conditions like P.Ca and BPH in the past decade, there has been an increasing realization by both biochemists and urologists, to have a better single marker or a combination of biochemical tests to differentiate the above conditions, to avoid frequency and unnecessary biopsies in nonmalignant conditions.

PSA is a marker specific for prostatic conditions and shown to be significant in all disease compared to controls. So, a rise in serum PSA and PAP indicates prostatitis or, in combination with these two tests, decreased serum calcium shows advanced disease.

\section{Competing Interests}

None of the contributing authors have any conflict of interests, including specific financial interests or relationships and affiliations relevant to the subject matter or materials discussed in the manuscript.

\section{References}

[1] P. Christudoss, R. Selvakumar, J. J. Fleming, and G. Gopalakrishnan, "Zinc status of patients with benign prostatic hyperplasia and prostate carcinoma," Indian Journal of Urology, vol. 27, no. 1, pp. 14-18, 2011.

[2] S. Bracarda, O. De Cobelli, C. Greco et al., "Cancer of the prostate," Critical Reviews in Oncology/Hematology, vol. 56, no. 3, pp. 379-396, 2005.

[3] J. E. McNeal, "Regional morphology and pathology of the prostate," American Journal of Clinical Pathology, vol. 49, no. 3, pp. 347-357, 1968.

[4] W. J. Catalona, A. W. Partin, K. M. Slawin et al., "Use of the percentage of free prostate-specific antigen to enhance differentiation of prostate cancer from benign prostatic disease: a prospective multicenter clinical trial," The Journal of the American Medical Association, vol. 279, no. 19, pp. 1542-1547, 1998.

[5] J. M. Young, D. J. Muscatello, and J. E. Ward, "Are men with lower urinary tract symptoms at increased risk of prostate cancer? A systematic review and critique of the available evidence," BJU International, vol. 85, no. 9, pp. 1037-1048, 2000.

[6] C. T. Brown, E. O’Flynn, J. Van Der Meulen, S. Newman, A. R. Mundy, and M. Emberton, "The fear of prostate cancer in men with lower urinary tract symptoms: should symptomatic men be screened?" BJU International, vol. 91, no. 1, pp. 30-32, 2003.

[7] D. F. Gleason and G. T. Mellinger, "Prediction of prognosis for prostatic adenocarcinoma by combined histological grading 
and clinical staging," The Journal of Urology, vol. 111, no. 1, pp. 58-64, 1974.

[8] N. A. Romas, "Prostatic acid phosphatase: current concepts," Seminars in urology, vol. 1, no. 3, pp. 177-185, 1983.

[9] S. C. Kukreja, A. Shanmugam, and T. E. Lad, "Hypocalcemia in patients with prostate cancer," Calcified Tissue International, vol. 43 , no. 6 , pp. $340-345,1988$.

[10] S. Kapur, "Phosphorus balance and prostate cancer," Indian Journal of Experimental Biology, vol. 37, no. 7, pp. 623-626, 1999.

[11] E. Kesse, S. Bertrais, P. Astorg et al., "Dairy products, calcium and phosphorus intake, and the risk of prostate cancer: results of the French prospective SU.VI.MAX (Supplémentation en Vitamines et Minéraux Antioxydants) study," British Journal of Nutrition, vol. 95, no. 3, pp. 539-545, 2006.

[12] K. M. Wilson, I. M. Shui, L. A. Mucci, and E. Giovannucci, "Calcium and phosphorus intake and prostate cancer risk: a 24y follow-up study," American Journal of Clinical Nutrition, vol. 101, no. 1, pp. 173-183, 2014.

[13] L. I. Stowell, L. E. Sharman, and K. Hamel, "An enzyme-linked immunosorbent assay (ELISA) for prostate-specific antigen," Forensic Science International, vol. 50, no. 1, pp. 125-138, 1991.

[14] A. B. Gutman and E. B. Gutman, "An 'ACID' phosphatase occurring in the serum of patients with metastasizing carcinoma of the prostate gland," Journal of Clinical Investigation, vol. 17, no. 4, pp. 473-478, 1938.

[15] H. J. Gitelman, "An improved automated procedure for the determination of calcium in biological specimens," Analytical Biochemistry, vol. 18, no. 3, pp. 521-531, 1967.

[16] N. W. Teitz, Fundamentals of Clinical Chemistry, W.B. Saunders, Philadelphia, Pa, USA, 2nd edition, 1976.

[17] K. Jung, J. Reiche, A. Boehme et al., "Analysis of subforms of free prostate-specific antigen in serum by two-dimensional gel electrophoresis: potential to improve diagnosis of prostate cancer," Clinical Chemistry, vol. 50, no. 12, pp. 2292-2301, 2004.

[18] J. Anim, E. Kehinde, M. Sheikh et al., "Serum prostate-specific antigen levels in middle eastern men with subclinical prostatitis," Medical Principles and Practice, vol. 16, no. 1, pp. 53-58, 2006.

[19] A. Taira, G. Merrick, K. Wallner, and M. Dattoli, "Reviving the acid phosphatase test for prostate cancer," Oncology, vol. 21, no. 8, pp. 1003-1010, 2007.

[20] L. Nguyen, A. Chapdelaine, and S. Chevalier, "Prostatic acid phosphatase in serum of patients with prostatic cancer is a specific phosphotyrosine acid phosphatase," Clinical Chemistry, vol. 36, no. 8, pp. 1450-1455, 1990.

[21] T. A. Stamey, N. Yang, and A. R. Hay, "Prostate-specific antigen as a serum marker for adenocarcinoma of the prostate," New England Journal of Medicine, vol. 317, no. 15, pp. 909-916, 1987.

[22] Ö. Yaman, Ç. Göğüş, Ö. Tulunay, Z. Tokatli, and E. Özden, "Increased prostate-specific antigen in subclinical prostatitis: the role of aggressiveness and extension of inflammation," Urologia Internationalis, vol. 71, no. 2, pp. 160-164, 2003.

[23] L. H. Simardi, M. Tobias-Machado, G. T. Kappaz, P. Taschner Goldenstein, J. M. Potts, and E. R. Wroclawski, "Influence of asymptomatic histologic prostatitis on serum prostate-specific antigen: a prospective study," Urology, vol. 64, no. 6, pp. 10981101, 2004.

[24] P. Raskin, C. J. McClain, and T. A. Medsger Jr., "Hypocalcemia associated with metastatic bone disease. A retrospective study," Archives of Internal Medicine, vol. 132, no. 4, pp. 539-543, 1973.
[25] M. Szentirmai, C. Constantinou, J. M. Rainey, and J. E. Loewenstein, "Hypocalcemia due to avid calcium uptake by osteoblastic metastases of prostate cancer," Western Journal of Medicine, vol. 163, no. 6, pp. 577-578, 1995.

[26] G. D. Ludwig, "Hypocalcemia and hypophosphatemia accompanying osteoblastic osseous metastases: studies of calcium and phosphate metabolism and parathyroid function," Annals of Internal Medicine, vol. 56, no. 4, pp. 676-677, 1962.

[27] H. G. Skinner and G. G. Schwartz, "Serum calcium and incident and fatal prostate cancer in the national health and nutrition examination survey," Cancer Epidemiology, Biomarkers \& Prevention, vol. 17, no. 9, pp. 2302-2305, 2008. 


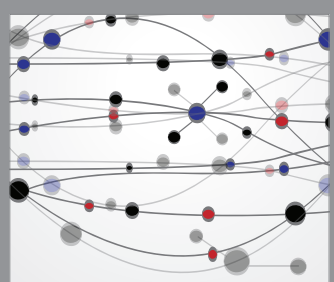

The Scientific World Journal
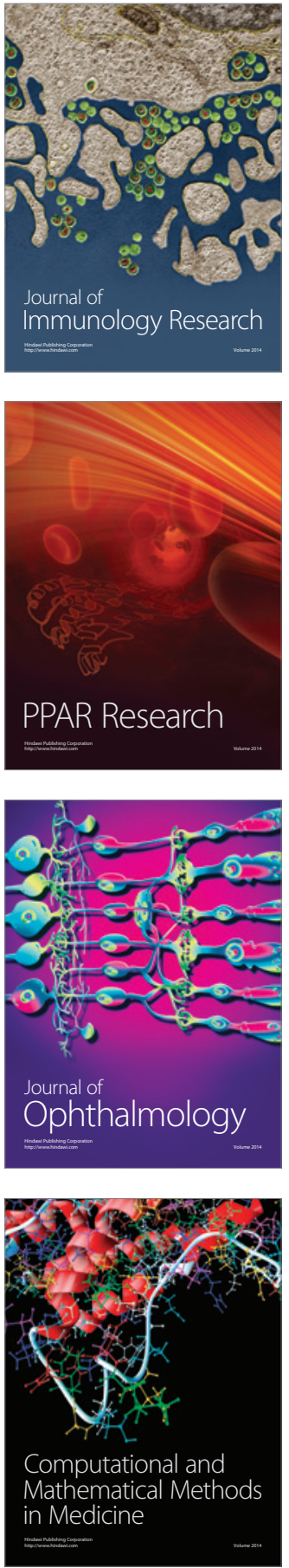

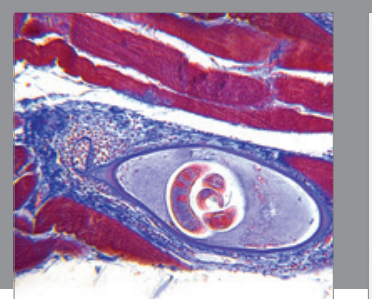

Gastroenterology Research and Practice
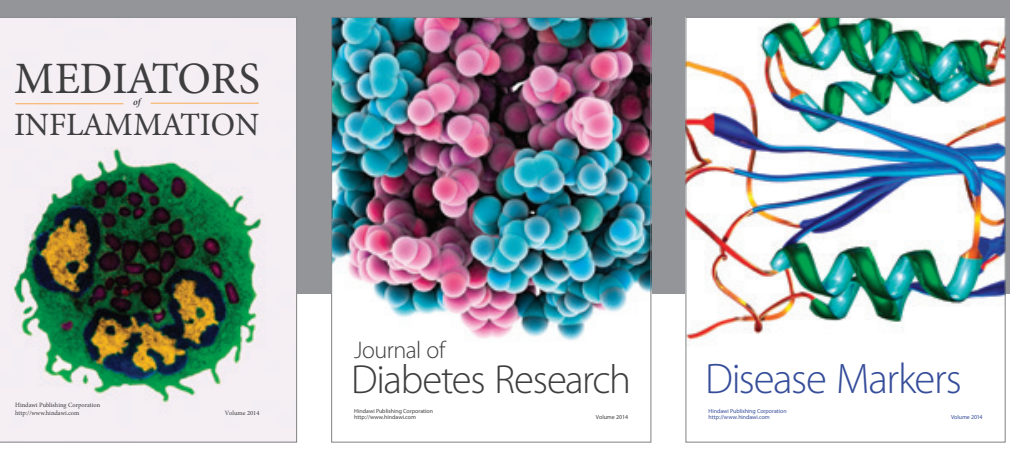

Disease Markers

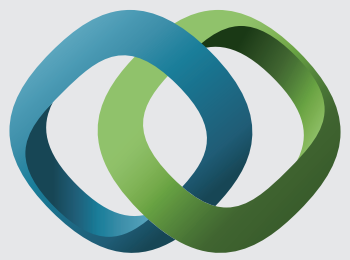

\section{Hindawi}

Submit your manuscripts at

https://www.hindawi.com
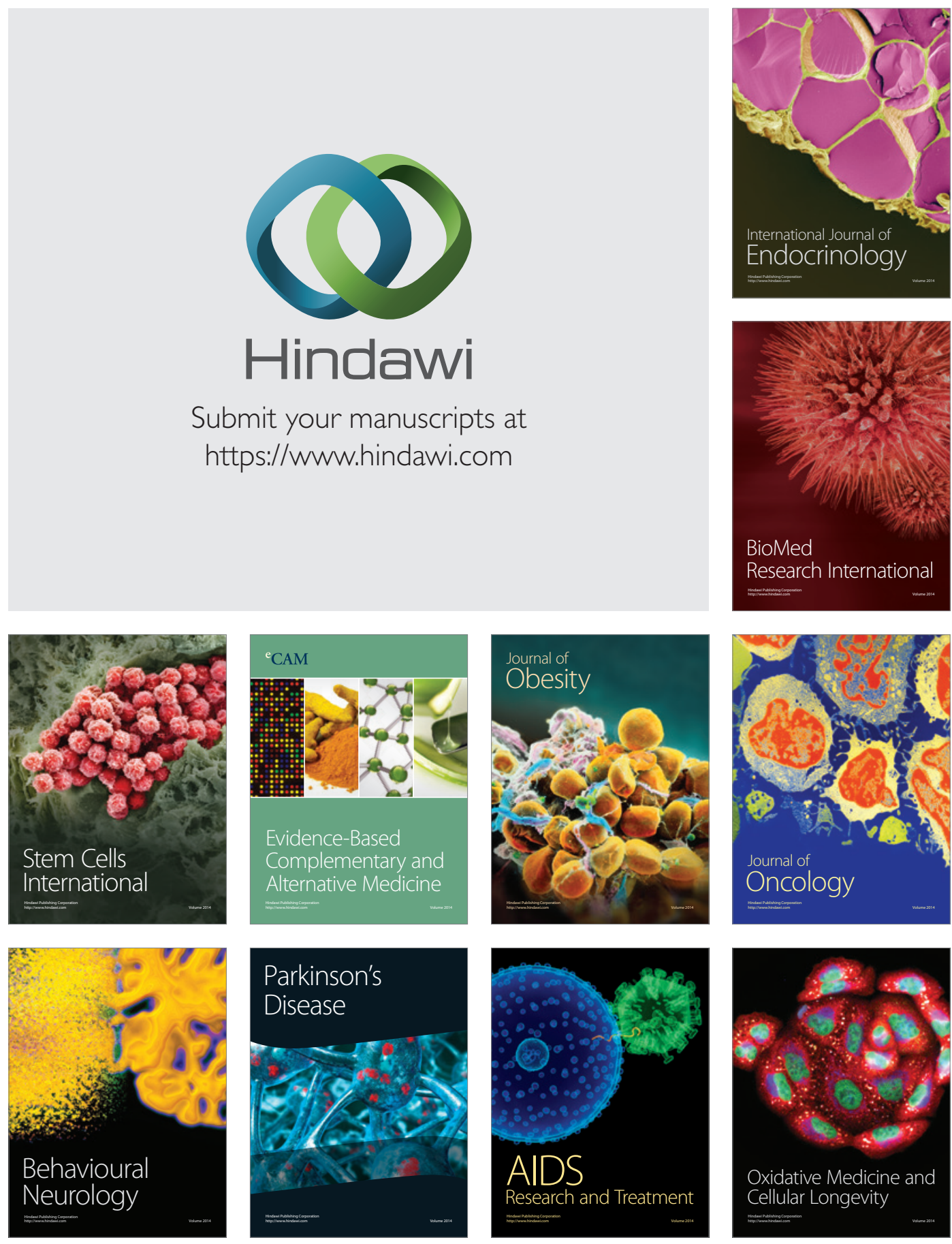